\title{
PREPARATION AND PURIFICATION OF A FLAME-RETARDANT POLYPHENYLPHOSPHONATE CONTAINING 4,4'-DIHYDROXYBENZOPHENONE
}

\author{
Graziele Vefago Boaventura Possenti ${ }^{1} \bowtie$, Aline Vieira de Souza ${ }^{2}$, Rodrigo Battisti $^{1}$, Juliani \\ Conti Martins Dominguini ${ }^{2}$, Lucas Dominguini ${ }^{1}$, Cintia Soares ${ }^{2}$, \\ Humberto Gracher Riella ${ }^{2}$
}

https://doi.org/10.23939/chcht16.01.095

\begin{abstract}
A polyphenylphosphonate containing 4,4'dihydroxybenzophenone was synthesized as a flame retardant. However, impurities were detected and may compromise its properties and thermal stability. Thus, a purification route based on water and hexane extraction with reflux was proposed. Results showed success in removing impurities, especially $\mathrm{P}-\mathrm{Cl}$ groups, without damaging the polymer.
\end{abstract}

Keywords: polyphenylphosphonate, flame retardant, purification, aqueous extraction, organic extraction.

\section{Introduction}

An increasing emphasis on the issue of polymer synthesis, as well as its application in several areas, has been observed in recent years. On the other hand, polymers present residual solvents, unreacted monomers and other impurities derived from their synthesis. The presence of such impurities can be problematic with regard to the application, making its purification necessary. ${ }^{1}$ Flameretardants are among polymers that have been synthesized recently. Although they do not completely eliminate combustion, these retardants interfere with the physical and chemical mechanism of combustion and improve the fire resistance of a polymer material. ${ }^{2,3}$

Phosphorus-containing flame-retardants have good fire resistance and low toxicity when compared to halogen-containing flame-retardants, so they are

\footnotetext{
${ }^{1}$ Federal Institute of Education, Science and Technology of Santa Catarina (IFSC),

campus Criciúma, Rodovia SC $443 \mathrm{~km} 1, \mathrm{n}^{\circ}$ 845, Vila Rica, Criciúma, Santa Catarina, Brazil, 88813-600

2 Chemical Engineering Department, Federal University of Santa Catarina (UFSC),

campus Trindade, Florianópolis, Santa Catarina, Brazil, 88040-900

$凶$ graziele.vefago@ifsc.edu.br

(c) Possenti, G.V.B.; de Souza, A.V.; Battisti, R.; Dominguini, J.C.M.; Dominguini, L.; Soares, C.; Riella, H.G., 2022
}

considered to be very efficient in many polymers and have been used in this field. ${ }^{4}$ Compounds containing P-C bonds are preferred as flame-retardants because they promote the formation of charcoal, high fireproof efficiency at low phosphorus concentration, thermal stability and easy synthesis. ${ }^{5,6}$ The action of these compounds may occur in the vapor phase by a radical mechanism to disrupt exothermic processes and suppress combustion. In this case, it is likely that the $\mathrm{PO}, \mathrm{P}$ and $\mathrm{P}_{2}$ species react with the $\mathrm{H}$ and $\mathrm{OH}$ radicals to form $\mathrm{HPO}{ }^{7}$ On the other hand, they can also act in the condensed phase. The compounds incorporated in polymeric materials act as acid precursors and the atoms participate in the formation of coal. Soon, a protective layer is formed to prevent further burning. ${ }^{8}$

Several phosphorus-containing compounds have been synthesized and used to improve flame retardancy in polymers, such as triphenyl phosphate (TPP), ${ }^{9}$ resorcinol bis(diphenyl phosphate) (RDP), ${ }^{10}$ bisphenol A bis(diphenyl phosphate) (BDP), ${ }^{11}$ poly(9-oxa-10-(2,5dihydro-xyphenyl)phospha-phenanthrene-10-oxide) phenylphosphonate (WLA-3), ${ }^{12}$ and phosphorus oxychloride $\left(\mathrm{POCl}_{3}\right) .{ }^{13}$ Kricheldorf et al. ${ }^{14}$ investigated the synthesis via a silyl method of flame-retardant polyphosphonates from monomers of phenylphosphonic dichloride with silylated biphenyldiol or diphenols. They concluded that the molecular weights of polyphosphonates synthesized via the silyl method are not higher than those prepared under optimum conditions by the conventional interfacial method or thermal condensation of the corresponding free phenols. Nevertheless, the silyl method has the advantage of a great versatility for the preparation of copolyesters from various acid chlorides. Dominguini ${ }^{15}$ also focused on the synthesis of a polymer containing phosphorus with flame retardant properties. The author used the interfacial polycondensation as the synthesis methodology to obtain a polyphenylphosphonate containing 4,4'-dihydroxybenzophenone. However, unidentified signals or bands not characteristic of 
polyphenylphosphonate were observed in the NMR and FTIR spectra, respectively. This indicates the presence of impurities from excess sub-products or reagents during the polymerization process. ${ }^{15,16}$

Purification of products is necessary to remove contaminants that may interfere with the application of the material, which will consequently lead to a decrease in the final cost of the product. Thus, the purification strategies to be employed must be satisfactory, fast, high yield, and robust. The key to successful and efficient purification is to select the most appropriate technique, optimize its performance to meet the requirements, and combine them in a logical way to maximize productivity and reduce the number of steps required. ${ }^{17}$ In addition, according to Wilkie and Morgan, ${ }^{18}$ the impurities present in polymers in general, more specifically in flame retardant polymers, can influence their thermal degradation characteristics, being recognized as a critical variable by manufacturers. Still according to the authors, it is sufficient to state, at this point, that the consequences of these impurities are generally those of promoting the overall degradation and can give rise to the slow thermal degradation and related deterioration in the properties of the polymer, often experienced when in use, and exposed to service temperatures well below their normal rapid degradation temperatures. Researches have been focused on the purification of reaction products and sub-products. Zagklis and Paraskeva, ${ }^{19}$ for example, optimized a solvent extraction process to purify phenolic compounds, followed by fractionation with membrane filtration and adsorption/desorption. Zeng et al. ${ }^{20}$ improved Soxhlet extraction for purification of polybrominated diphenyl ethers (PBDEs). Iliescu et $a l^{21}$ purified a polyphosphonate with washing in distilled water and by the dissolution/precipitation method.

One of the basic operations of separation of materials is extraction. Extraction is a method of chemical separation, which can be applied in different ways. The principle of extraction is to remove substances that may negatively influence the sample. In addition, it is used to concentrate solutions and transport compounds between different solvents. Among some types of extraction, liquid-liquid extraction is highlighted. Liquid-liquid extraction is based on the displacement of a solute from one solvent to another according to the solubility equilibrium, in which the solvents are immiscible. This equilibrium solubility depends directly on the temperature and pressure of the system. ${ }^{22}$ Thus, purification favors the application of the product, besides creating reuse or recycling opportunities of sub-products with some added value. Furthermore, Dominguini ${ }^{15}$ indicated the presence of impurities from by-products or reagents in excess of the polymerization process of the flame-retardant polymer and highlighted the need for its purification.
In this context, the present work aims to propose a purification route for a polyphenylphosphonate containing 4,4'-dihydroxybenzophenone synthesized for flame retardant applications.

\section{Experimental}

\subsection{Materials}

The materials used in the synthesis and purification route of the polyphenylphosphonate polymer were: phenylphosphonic dichloride (PPDC), 4,4-dihydroxybenzophenone (DHBP) and benzyltriphenylphosphonium chloride (BTPC), supplied by Sigma Aldrich (USA). Dichloromethane (DCM), tetradhydrofuran (THF) hexane and sodium hydroxide, supplied by Vetec, Neon and Dynamic (Brazil), respectively, and distilled water. All reagents were of analytical grade and were used without any prior purification.

\subsection{Methods}

\subsubsection{Synthesis of the polyphenylphosphonate}

To obtain the polyphenylphosphonate (PPP), an optimized version of the method presented by Dominguini ${ }^{15}$ was applied (Fig. 1). For this, a jacketed glass reactor of $200 \mathrm{~mL}$ was used. The system was maintained at reflux, at controlled temperature and in agitation to control the reaction. Initially, a $1.0 \mathrm{~mol} / \mathrm{L}$ $\mathrm{NaOH}$ solution and a $0.1 \mathrm{~mol} / \mathrm{L}$ BTPC solution dissolved in DCM were prepared. The solutions were added to the reactor and stirred for $30 \pm 1 \mathrm{~min}$ at $277 \mathrm{~K}$ to yield a biphasic mixture. Subsequently, a solution of DHBP $(0.007 \mathrm{~mol} / \mathrm{L})$ dissolved in DCM and $0.0114 \mathrm{~mol}$ of PPDC, were simultaneously added to the reactor. The resulting solution was kept under stirring for $4 \mathrm{~h}$ at the temperature of $277 \pm 0.1 \mathrm{~K}$. After this reaction period, the synthesized polymer was precipitated with cold hexane and water. For evaporation of solvent residues, the synthesized polymer was oven dried at $333 \pm 1 \mathrm{~K}$.

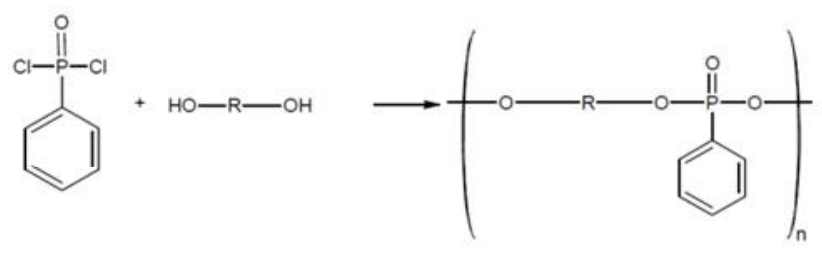

Fig. 1. Generic reaction to obtain a phosphorous polymer

\subsubsection{Solubility test}

The solubility test was performed with the objective of identifying the solvent in which each reagent is soluble. It is thus possible to define what is present in 
each liquid phase resulting from the synthesis. For this purpose, $0.50 \pm 0.01 \mathrm{~g}$ of epy reagent was used and solubilized in $5.0 \pm 0.1 \mathrm{~mL}$ of solvent.

\subsubsection{Purification}

\section{of the polyphenylphosphonate}

For purification of the polyphenylphosphonate (PPP), a two-step purification route was applied. In the first step, the polymer was subjected to an aqueous extraction and in the second step it was subjected to an organic extraction. Fig. 2 shows a flowchart of the analytical route applied in the purification of PPP.

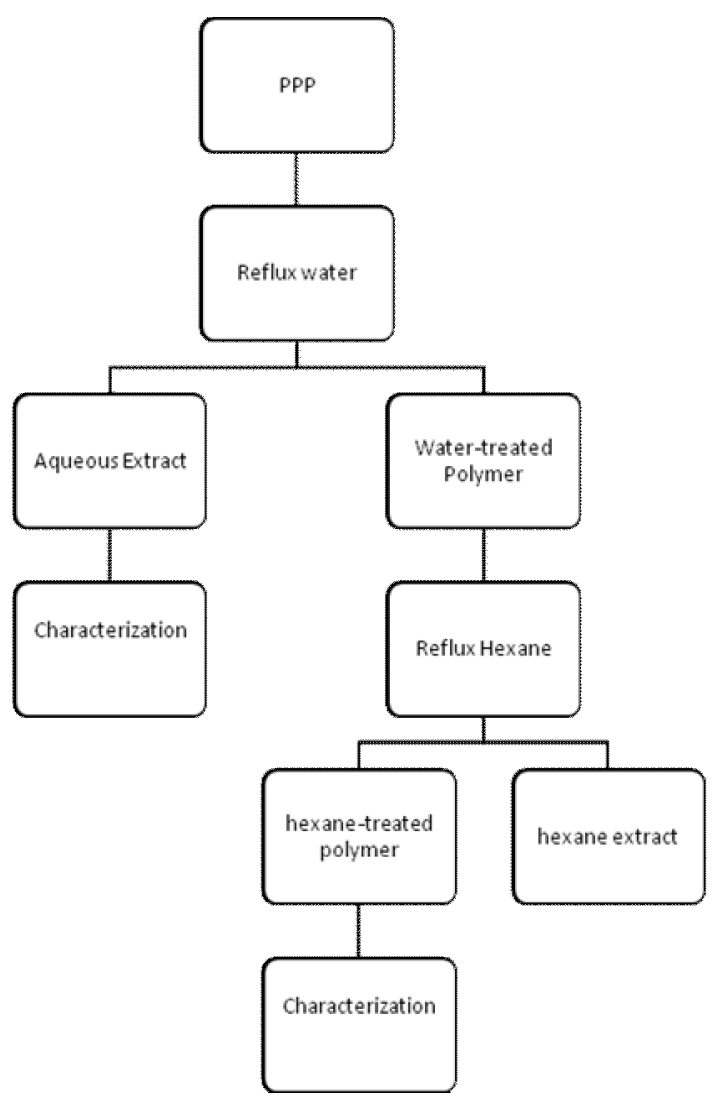

Fig. 2. Organization of the analytical route applied in the purification and characterization of PPP

Initially, in the first step of the purification route, $1.50 \pm 0.01 \mathrm{~g}$ of the polymer was refluxed in distilled water. For this, the sample was added to a $250 \mathrm{~mL}$ flat bottom flask, with $100 \mathrm{~mL}$ of distilled water, coupled to a condenser that is maintained at the temperature of $288 \pm 1 \mathrm{~K}$. The extraction system was heated to the temperature of $343 \pm 1 \mathrm{~K}$ for $50 \pm 1 \mathrm{~min}$ after the reflux began. The sample was then removed from the reflux flask and taken to the oven for drying at the temperature of $333 \pm 1 \mathrm{~K}$. In the second step, the polymer resulting from the aqueous extraction process was refluxed in hexane. For this, the sample was transferred to a $250 \mathrm{~mL}$ flat bottom flask and $100 \mathrm{~m}$ hexane was added. The flask was coupled to a condenser maintained at the temperature of $288 \pm 1 \mathrm{~K}$. The extraction set was heated to the temperature of $333 \pm 1 \mathrm{~K}$. After the beginning of reflux, the system was maintained for $50 \pm 1$ min under heating and stirring and after this process, the polymer was removed from the flask, washed with a little distilled water at room temperature and dried in an oven at $333 \pm 1 \mathrm{~K}$.

\subsubsection{Characterization of the extracts resulting from purification}

Gravimetric analysis was used to determine total solids. For this, an aliquot of the sample was added in a dry and heavy beaker. The sample was left in the oven at $378 \pm 1 \mathrm{~K}$ for $24 \mathrm{~h}$. Subsequently it was removed, stored in a desiccator until room temperature, and then weighed, after which the TS concentration was calculated. To determine the conductivity of the aqueous samples, the conductometric method was applied. To carry out the readings, a benchtop conductivity meter (mCA 150, Tecnopon), calibrated with a standard solution of $146.9 \mu \mathrm{S} \cdot \mathrm{cm}^{-1}$ was used. In order to determine the sodium concentration present in the aqueous samples, analyses were carried out. For this, a flame photometer (Analyser, model 910) was used. The determination of chloride concentration was performed by titration using the Mohr method. For titration, a previously prepared and standardized silver nitrate solution $\left(\mathrm{AgNO}_{3}\right) 0.1 \mathrm{~mol} / \mathrm{L}$ was used.

\subsubsection{Characterization of the purified polymer}

MALDI-TOF mass spectrometer. The samples were analyzed on a Bruker MALDI-TOF mass spectrometer (AutoFlex III Smartbean). The method was applied for the purpose of determining the molar mass of polyphenylphosphonate, before and after treatment. Initially, the samples were diluted in tetrahydrofuran (THF). $1 \mu \mathrm{L}$ of the 2,5-dihydroxybenzoic acid matrix (DHB) was applied and crystallized at room temperature in a MALDI target plate (Bruker Daltonics). Next, $3 \mu \mathrm{L}$ of each polyphenylphosphonate sample was applied to the DHB matrix crystallized on the plate. The spectrometer was calibrated with peptide reagent (Bruker) for the range of 1000 to 3500 Da. Mass spectra (MS) by MALDI-TOF were obtained in the positive ion reflection mode, applying a $100 \mathrm{~Hz}$ frequency laser, with $80 \%$ of full load, in the detection range of $400-4000 \mathrm{Da}$.

Fourier Transform Infrared Spectrophotometry (FTIR). A Shimadzu model spectrometer (IR Prestige 21) was used for the FTIR tests, using the $\mathrm{KBr}$ technique in the wave number range of $500-4000 \mathrm{~cm}^{-1}$. 
Thermal Analyses. For thermogravimetric analysis (TGA), $10 \mathrm{mg}$ of sample were prepared on an STA (model 443 F3 Jupiter, Netzsch) under $\mathrm{N}_{2}$ atmosphere $(20 \mathrm{~mL} / \mathrm{min})$ at the heating rate of $10 \mathrm{~K} / \mathrm{min}$. Differential scanning calorimetry (DSC) was performed by using a Perkin Elmer/Jade DSC (Intracooler SP) and Pyris Series Perkin Elmer software. The samples were analyzed in the temperature range of $253-503 \mathrm{~K} / \mathrm{min}$ cooled to $253 \mathrm{~K}$ keeping isotherm for $10 \mathrm{~min}$ and heating rate $10 \mathrm{~K} / \mathrm{min}$ keeping isotherm for $10 \mathrm{~min}$, and $\mathrm{N}_{2}$ flow rate of $30 \mathrm{~mL} / \mathrm{min}$.

\section{Results and Discussion}

\subsection{Solubility Test of the Polyphenylphosphonate and Reagents Used in the Synthesis}

From the results presented in Table 1, it is possible to find $\mathrm{NaOH}$ and $\mathrm{BTPC}$ in the aqueous phase. In addition, the organic phase is composed of two solvents, hexane and dichloromethane, since both are miscible. In the organic phase, it is possible to find the PPDC monomer that did not polymerize. Since the DHBP mono- mer is insoluble or partially soluble in the solvents present in the synthesis, if an unpolymerized monomer is present, the same may precipitate with the polymer or remain in the system and be removed with the solid phase from the synthesis.

\subsection{Purification of the Polyphenylphosphonate}

In the first step of the purification, an aqueous extract was obtained. Table 2 shows the results obtained in the analysis of total solids, conductivity, sodium, and chloride in the extract obtained.

From the results, it is possible to affirm that there was removal of impurities in the reflux step in water. The hexane resulting from the second extraction step left a body at the bottom when standing after reflux, and presented $500 \mathrm{mg} / \mathrm{L}$ of soluble solids. The solid obtained in the reflux step in hexane was classified as a byproduct of the purification process and characterized. Solubility and FTIR assays were performed to characterize the subproduct. Table 3 shows the solubility test results determined for the sub-product obtained in the reflux step in hexane.

Table 1. Results of the solubility test of the reagents, the polymer and the solvents used in the polyphenylphosphonate synthesis

\begin{tabular}{|c|c|c|c|c|c|}
\hline Reagent & Physical state & Distilled water & Hexane & DCM & THF \\
\hline PPDC & liquid & miscible & immiscible & miscible & miscible \\
\hline DHBP & solid & insoluble & insoluble & partially soluble & soluble \\
\hline BTPC & solid & soluble & insoluble & insoluble & insoluble \\
\hline NaOH & solid & soluble & insoluble & insoluble & insoluble \\
\hline PPP & solid & insoluble & insoluble & insoluble & soluble \\
\hline DCM & liquid & immiscible & miscible & - & miscible \\
\hline Hexane & liquid & immiscible & - & miscible & miscible \\
\hline
\end{tabular}

Table 2. Results of the total solids, conductivity, sodium, and chloride tests for the aqueous extract

\begin{tabular}{|c|c|}
\hline Analysis & Result \\
\hline Total solids & $500 \mathrm{mg} / \mathrm{L}$ \\
\hline Electric conductivity & $165.30 \mu \mathrm{S} / \mathrm{cm}$ \\
\hline Sodium & $15.87 \mathrm{mg} / \mathrm{L}$ \\
\hline Chlorides & $<10 \mathrm{mg} / \mathrm{L}$ \\
\hline
\end{tabular}

Table 3. Results of the solubility test of the sub-product obtained in the reflux stage in hexane compared to results obtained for the solid reagents used in the polymerization reaction

\begin{tabular}{|c|c|c|c|c|}
\hline Reagent & Distilled water & Hexane & DCM & THF \\
\hline Sub-product & insoluble & insoluble & insoluble & soluble \\
\hline DHBP & insoluble & insoluble & partially soluble & soluble \\
\hline BTPC & soluble & insoluble & insoluble & insoluble \\
\hline $\mathrm{NaOH}$ & soluble & insoluble & insoluble & insoluble \\
\hline
\end{tabular}


Analyzing the obtained results, it is possible to note that the byproduct presents characteristics similar to the monomer DHBP. In order to confront the present connections in the sub-product and DHBP, FTIR analysis was performed. As shown in Fig. 3, the presence of DHBP-like bands was evidenced in the sub-product sample.

Bands characteristic of DHBP are found in 1510 and $1446 \mathrm{~cm}^{-1}$, corresponding to the $\mathrm{C}=\mathrm{C}$ aromatic bond. ${ }^{15,23}$ The band at $1600 \mathrm{~cm}^{-1}$ corresponds to the $\mathrm{C}=\mathrm{O}$ group and the band at $853 \mathrm{~cm}^{-1}$ corresponds to the $\mathrm{C}-\mathrm{H}$ aromatic bond. ${ }^{15,24-26}$ Fig. 4 shows the detailed diagram of the purification route and the parameters that showed positive results are exposed.

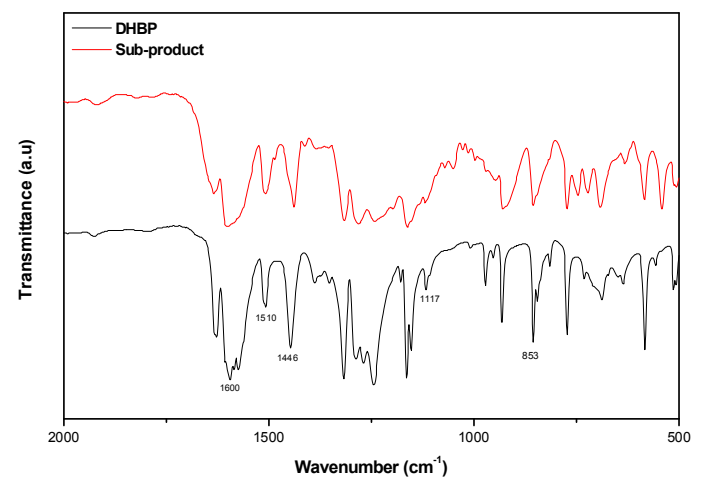

Fig. 3. FTIR spectra for the sub-product and the 4,4'hydroxybenzophenone monomer

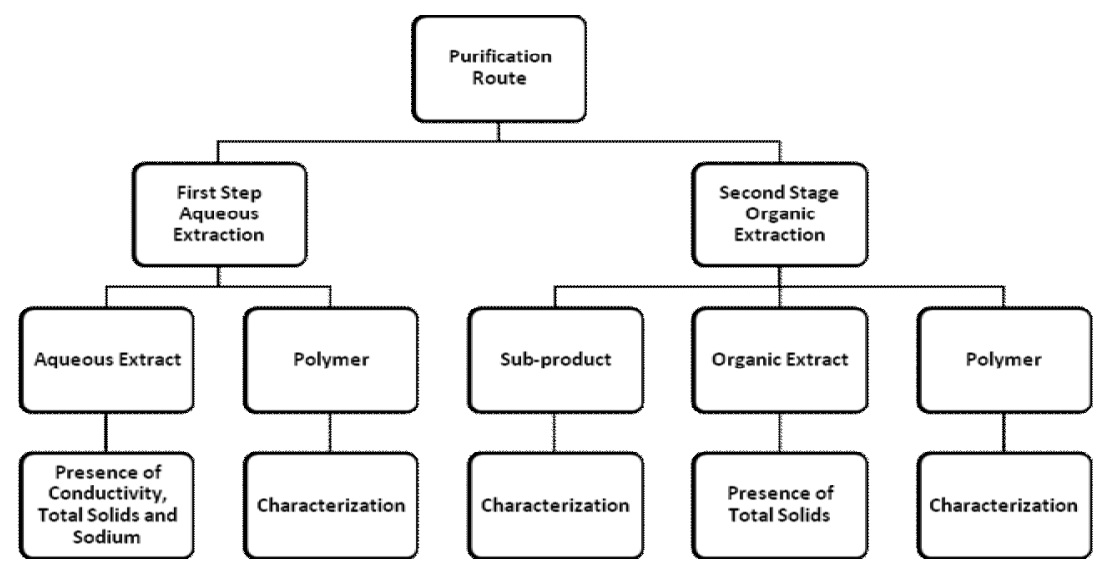

Fig. 4. Detailed diagram of the purification route

\subsection{Characterization of the Purified Polymer}

\subsubsection{MALDI-TOF mass spectrometer}

By observing the presented results, it is possible to verify that impurities were removed, since the treatment resulted in a sub-product and the laboratory tests presented soluble solids in the obtained extracts. The MALDI-TOF spectra shown in Figure 5 show the molar masses obtained for the polyphenylphosphonate polymer (or in this case, being classified as an oligomer) before and after being subjected to the purification route. The results showed similar peaks between the purified and in natura sample, that is, the molar masses were conserved during the purification process. Thus, the purification route does not affect the polymer structure, therefore, it is possible to apply the method.

\subsubsection{Fourier transform infrared spectrophotometry (FTIR)}

Fig. 6 shows a comparison between the FTIR spectra of the in natura and purified samples. The results show that the spectra are similar, not characterizing the decomposition of the polymer molecule and its chemical bonds.

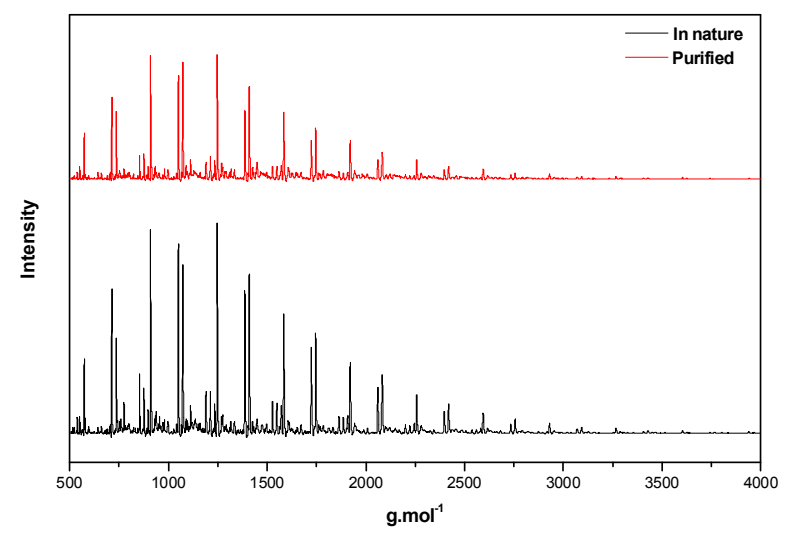

Fig. 5. MALDI-TOF results of the polyphenylphosphonate polymer in natura before and after purification route

The bands characteristic of polyphenylphosphonate are present in the spectra without being altered by the purification, which are located in the regions 1610, 1439, 
1239-1320, and $921 \mathrm{~cm}^{-1}$, corresponding to the presence of the $\mathrm{C}=\mathrm{O}, \mathrm{P}-\mathrm{C}, \mathrm{P}=\mathrm{O}$ and $\mathrm{P}-\mathrm{O}-\mathrm{C}$ aromatic groups, respectively. ${ }^{23,25,27,28}$ In addition, it is possible to observe a change in bands of 686 and $583 \mathrm{~cm}^{-1}$, corresponding to the $\mathrm{P}-\mathrm{Cl}$ bond. ${ }^{15,29}$ Peaks pertaining to samples treated in this region are minimized, which corresponds to the reduction of this grouping in the polymer. Since the $\mathrm{P}-\mathrm{Cl}$ group represents impurity in the sample, it can be said that the method was effective in removing impurities.

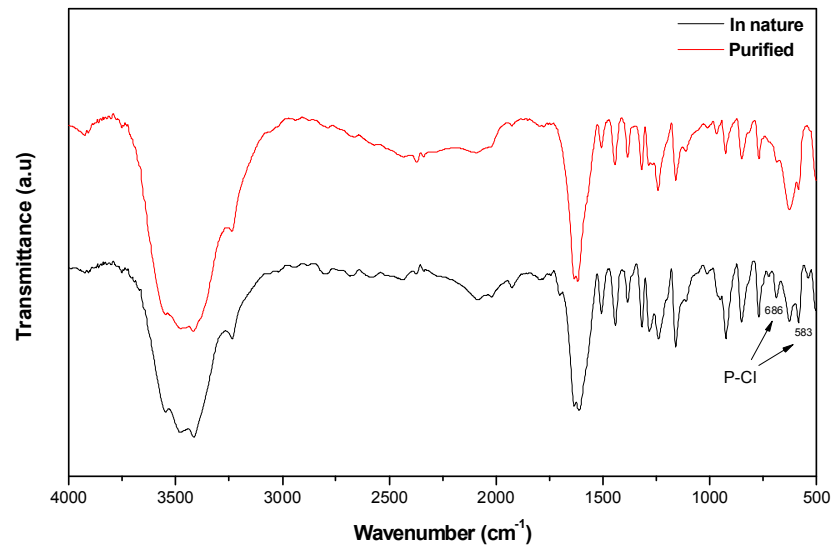

Fig. 6. FTIR results of the polyphenylphosphonate polymer in natura before and after the purification route, in the wave range of $4000-500 \mathrm{~cm}^{-1}$

\subsubsection{Thermal analyses}

TGA analysis demonstrated that the polyphenylphosphonate polymer sample showed three bands

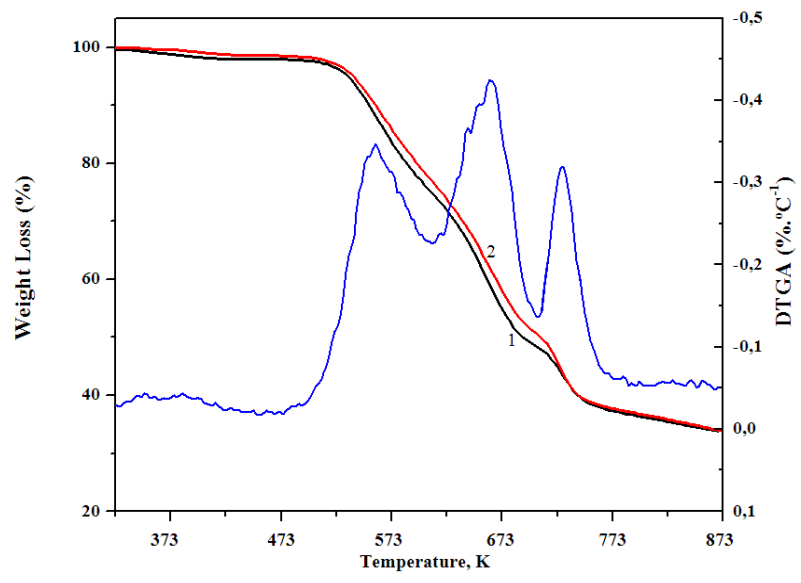

Fig. 7. TGA and DTGA results of the polyphenylphosphonate polymer in nature (1) and after the purification route (2)

\section{Conclusions}

A novel purification route for the polyphenylphosphonate containing 4,4'-dihydroxybenzophenone was proposed. The method can be applied without damage to of mass loss (Fig. 7). The determined mass loss temperatures were 558, 662 and $728 \mathrm{~K}$ for both samples. By observing the thermogram, it can be seen that the bands of mass loss of the polyphenylphosphonate polymer were not significantly altered by the application of the purification route. However, it can be verified that the purified sample presented slightly better thermal stability than that in nature sample, characterized by the reduction of mass loss. The mass loss derivative (DTGA) represents the degradation temperature peaks, with the maximum degradation in the components being $662 \mathrm{~K}$. The minimum degradation range of the polyphenylphosphonate polymer is above the working range used in the purification route. Thus, the temperature applied would not influence the structure of the molecule.

Fig. 8 shows the DSC thermogram of the polyphenylphosphonate polymer before and after the application of the purification route. The DSC results showed one glass transition temperature for both samples. From the thermogram, it can be seen that the determined glass transition temperatures were about $338 \mathrm{~K}$. This result is very similar to that found by Dominguini et al., ${ }^{30}$ who synthesized a polyphosphate polymer with bisphenol (BHBF) and dichloride of phenylphosphonic (PPDC); the authors identified a vitreous transition temperature for this polymer about $339 \mathrm{~K}$. It is can be seen also that the polymer melting temperature is about $475 \mathrm{~K}$ for both samples, before and after the purification steps. Thus, it is significant to say that the result obtained after the purification route was satisfactory, not degrading the polymer molecule.

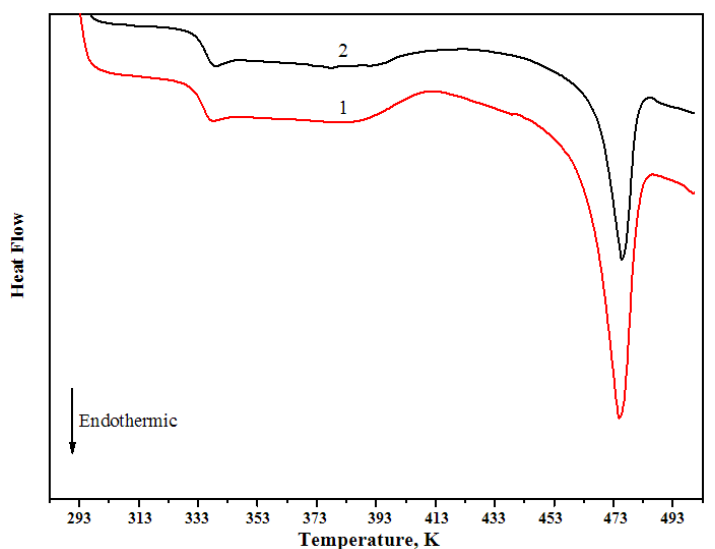

Fig. 8. DSC results of the polyphenylphosphonate polymer in nature (1) and after purification route (2)

the polymer. Removal of impurities is observed through the FTIR, MALDI-TOF, TGA and DSC spectra associated with the conductivity, chlorides, sodium and solids results. The FTIR spectrum clearly shows the reduction of the $\mathrm{P}-\mathrm{Cl}$ group, an impurity in the final 
product of synthesis. In addition, the sub-product from the organic extraction stage has characteristics similar to the 4,4'-dihydroxybenzophenone monomer. The FTIR spectrum presented the bands characteristic of the clusters present in 4,4'-dihydroxybenzophenone. The applied route allowed the purification of the polyphenylphosphonate, without damage to the molecule, besides recovering the DHBP reagent, which contributes to increase in the efficiency of the final product and reduces the environmental impact.

\section{Acknowledgements}

The authors thank the financial support from IFSC (Federal Institute of Santa Catarina). To CEBIME (UFSC) for performing the MALDI-TOF tests.

\section{References}

[1] Chattopadhyay, P.; Shekunov, B.; Gibson, K. US 7745566B2, Jun. 29, 2010.

[2] Rethwisch, D.; Callister, W. Ciência e Engenharia de Materiais: Uma Introdução; LTC: Rio de Janeiro, 2012.

[3] Döring, M.; Pfaendner, R.: Plástico Ind., 2016, 4, 32.

[4] Yemisci, F.; Yesil, S.; Aytac, A. Improvement of the Flame Retardancy of Plasticized Poly(Lactic Acid) by Means of Phosphorus-Based Flame Retardant Fillers. Fire Mater. 2017, 41, 964-972. https://doi.org/10.1002/fam.2440

[5] Ren, H.; Sun, J.; Wu, B.; Zhou, Q. Synthesis and Properties of a Phosphorus-Containing Flame Retardant Epoxy Resin Based on Bis-phenoxy (3-hydroxy) Phenyl Phosphine Oxide. Polym. Degrad. Stabil. 2007, 92, 956-961.

https://doi.org/10.1016/j.polymdegradstab.2007.03.006

[6] Faghihi, K.; Zamani, K. Synthesis and Properties of Novel Flame-Retardant Poly(amide-imide)s Containing Phosphine Oxide Moieties in Main Chain by Microwave Irradiation. J. Appl. Polym. Sci. 2006, 101, 4263-4269. https://doi.org/10.1002/app.23580 [7] Lu, S-Y.; Hamerton, I. Recent Developments in the Chemistry of Halogen-Free Flame Retardant Polymers. Prog. Polym. Sci. 2002, 27, 1661-1712. https://doi.org/10.1016/S00796700(02)00018-7

[8] Zhao, W.; Li, B.; Xu, M.; Zhang, L.; Liu, F.; Guan, L. Synthesis of a Novel Flame Retardant Containing Phosphorus and Sulfur and its Application in Polycarbonate. Polym. Eng. Sci. 2012, 52, 23272335. https://doi.org/10.1002/pen.23192

[9] Swoboda, B.; Buonomo, S.; Leroy, E.; Lopez-Cuesta, J.-M. Fire Retardant Poly(ethylene terephthalate)/polycarbonate/triphenyl Phosphite Blends. Polym. Degrad. Stabil. 2008, 93, 910-917. https://doi.org/10.1016/j.polymdegradstab.2008.02.003 [10] Pawlowski, K.H.; Schartel, B. Flame Retardancy Mechanisms of Triphenyl Phosphate, Resorcinol Bis(Diphenyl Phosphate) and Bisphenol A Bis(Diphenyl Phosphate) in

Polycarbonate/Acrylonitrile-Butadiene-Styrene Blends. Polym. Int. 2007, 56, 1404-1414. https://doi.org/10.1002/pi.2290

[11] Karrasch, A.; Wawrzyn, E.; Schartel, B.; Jäger, C. Solid-State NMR on Thermal and Fire Residues of Bisphenol A

Polycarbonate/Silicone Acrylate Rubber/Bisphenol A Bis(DiphenylPhosphate $) /(\mathrm{PC} / \mathrm{SiR} / \mathrm{BDP})$ and $\mathrm{PC} / \mathrm{SiR} / \mathrm{BDP} /$ zinc Borate (PC/SiR/BDP/ZnB) - Part I: PC Charring and the Impact of BDP and ZnB. Polym. Degrad. Stabil. 2010, 95, 2525-2533. https://doi.org/10.1016/j.polymdegradstab.2010.07.034 [12] Wie, L.-L.; Wang, D.-Y.; Chen, H.-B.; Chen, L.; Wang, X.-L.; Wang, Y.-Z. Effect of a Phosphorus-Containing Flame Retardant on the Thermal Properties and Ease of Ignition of Poly(Lactic acid). Polym. Degrad. Stabil. 2011, 96, 1557-1561.

https://doi.org/10.1016/j.polymdegradstab.2011.05.018

[13] Li, Q.; Jiang, P.; Wie, P. Synthesis, Characteristic, and Application of New Flame Retardant Containing Phosphorus, Nitrogen, and Silicon. Polym. Eng. Sci. 2006, 46, 344-350. https://doi.org/10.1002/pen.20472

[14] Kricheldorf, H.R.; Koziel, H.; Witek, E. New Polymer Syntheses, 25. Synthesis of Flame-Retardant Poly(Phenyl Phosphonate)s from Silylated Biphenyldiols and Diphenols. Die Makromol. Chemie, Rapid Commun. 1988, 9, 217-222.

https://doi.org/10.1002/marc.1988.030090404

[15] Dominguini, L. Síntese e Caracterização de um

Polifenilfosfonato Contendo 4,4'-Dihidroxibenzofenona com Potencial Aplicação como Agente Retardante de Chamas em Materiais Poliméricos; Universidade Federal de Santa Catarina, 2015.

[16] Martins, J.; Menegaro, D.; Miguel, T. et al.: $22^{\circ}$ Congresso Brasileiro de Engenharia e Ciência dos Materiais/CBECiMat. Natal, 2016, 8027-8035.

[17] Bala, M.; Ismail, N.A.; Mel, M.; Jami, M.S.; Salleh, H.M.; Amid, A. Bromelain Production: Current Trends and Perspective. Arch. des Sci. 2012, 65, 369-399.

[18] Wilkie, C.; Morgan, A. Fire Retardancy of Polymeric Materials; CRC Press: New York, 2009.

[19] Zagklis, D.P.; Paraskeva, C.A. Purification of Grape Marc Phenolic Compounds through Solvent Extraction, Membrane Filtration and Resin Adsorption/Desorption. Sep. Purif. Technol. 2015, 156, 328-335. https://doi.org/10.1016/j.seppur.2015.10.019 [20] Zeng, Y.-H.; Luo, X.-J.; Chen, H.-S.; Chen, S.-J.; Wu, J.-P.; Mai, B.-X. Method for the Purification of Polybrominated Diphenyl Ethers in Sediment for Compound-Specific Isotope Analysis. Talanta 2013, 111, 93-97.

https://doi.org/10.1016/j.talanta.2013.02.036

[21] Iliescu, S.; Plesu, N.; Popa, A.; Macarie, L.; Ilia, G. Green Synthesis of Polymers Containing Phosphorus in the Main Chain. Comptes. Rendus. Chim. 2011, 14, 647-651.

https://doi.org/10.1016/j.crci.2010.07.002

[22] Hage, D.; Carr, J. Química Analítica e Análise Quantitativa; Pearson Prentice Hall: São Paulo, 2012.

[23] Nguyen, T.-M.; Chang, S. Condon, B.; Thomas, T.P.; Azadi, P. Thermal Decomposition Reactions of Cotton Fabric Treated with Piperazine-Phosphonates Derivatives as a Flame Retardant. J. Anal. Appl. Pyrolysis 2014, 110, 122-129.

https://doi.org/10.1016/j.jaap.2014.08.006

[24] Feng, J.; Ge, Z.; Chai, C.; Wang, S.; Yu, D.; Wu, G., Luo, Y. Flame Retardant Modification of Waterborne Polyurethane Fabric Coating Agent with High Hydrostatic Pressure Resistance. Prog. Org. Coatings 2016, 97, 91-98.

https://doi.org/10.1016/j.porgcoat.2016.03.020

[25] Huo, S.; Wang, J.; Yang, S.; Wang, J.; Zhang, B.; Zhang, B.; Chen, X.; Tang, Y. Synthesis of a Novel Phosphorus-Nitrogen Type Flame Retardant COmposed of Maleimide, Triazine-Trione, and Phosphaphenanthrene and its Flame Retardant Effect on Epoxy Resin. Polym. Degrad. Stabil. 2016, 131, 106-113.

https://doi.org/10.1016/j.polymdegradstab.2016.07.013

[26] Saucă, S.; Giamberini, M.; Reina, J.A. Flame Retardant Phosphorous-Containing Polymers Obtained by Chemically 
Modifying poly(Vinyl alcohol). Polym. Degrad. Stabil. 2013, 98 , 453-463. https://doi.org/10.1016/j.polymdegradstab.2012.07.045 [27] Ding, H.; Huang, K.; Li, S.; Xu, L.; Xia, J.; Li, M.; et al.: Synthesis of a Novel Phosphorus and Nitrogen-Containing BioBased Polyol and its Application in Flame Retardant Polyurethane Foam. J. Anal. Appl. Pyrolysis 2017, 128, 102-113. https://doi.org/10.1016/j.jaap.2017.10.020

[28] Li, N.; Jiang, G.; Zhou, G. Synthesis and Characterization of Cyclic Bisphenol A (Phenylene Phosphonate) Oligomer and its Flame Retardancy Application. Polym. Degrad. Stabil. 2015, 122, 161-168. https://doi.org/10.1016/j.polymdegradstab.2015.11.003

[29] Wang, D.-Y.; Song, Y.-P.; Lin, L.; Wang, X.-L.; Wang, Y.-Z. A Novel Phosphorus-Containing Poly(Lactic Acid) toward its Flame Retardation. Polymer 2011, 52, 233-238. https://doi.org/10.1016/j.polymer.2010.11.023

[30] Dominguini, L.; Martinello, K.; Peterson, M.; Riella, H.G.; Fiori, M.A. Synthesis of Polyphosphate Polymer Employing the Bisphenol (BHBF) and the Dichloride of Phenylphosphonic (PPDC): Evaluation of the Thermal Characteristics. Curr. Trends
Anal. Bioanal. Chem. 2019, 3, 114-124.

https://doi.org/10.36959/525/446

Received: November 01, 2019 / Revised: February 06, 2020, Accepted: June 12, 2020

\section{ПРИГОТУВАННЯ ТА ОЧИЩЕННЯ АНТИПІРЕНУ - ПОЛІФЕНІЛФОСФОНАТУ, ЩО МІСТИТЬ 4,4'- ДИГІДРОКСИБЕНЗОФЕНОН}

Анотація. Поліфенілфосфонат, щзо містить 4,4'-дигідроксибензофенон, синтезований як антипірен. Виявлено домішки, які можуть погіршити його властивості та термостійкість. Запропоновано очищення на основі екстракиіі води та гексану, внаслідок якого домішки, особливо $\mathrm{P}-\mathrm{Cl}$ групи, успішно видалені без пошкодження полімеру.

Ключові слова: поліфенілфосфонат, антипірен, очищзення, водна екстракція, органічна екстракиія. 